\title{
Sociologia e ensino superior: encontro ou desencontro?
}

CARLOS BENEDITO MARTINS*

\section{Resumo}

O artigo aborda determinados marcos que têm caracterizado a relação entre sociologia e a análise dos sistemas de ensino na modernidade, privilegiando nessa relação o sistema de ensino superior. Salienta que a temática da educação ocupou uma posição destacada na obra de determinados autores clássicos da sociologia ao analisar a constituição do processo de modernidade. Ressalta que o sistema de ensino, destacadamente o ensino superior, tem ocupado uma posição estratégica nas sociedades contemporâneas em função da complexa relação que mantém com as esferas econômica, política e cultural em distintos contextos societários. Destaca a tendência existente na sociologia contemporânea de abordar o sistema de ensino como um subcampo especializado no interior da disciplina. Salienta que a tendência de abordar o sistema de ensino superior a partir de diversas temáticas especializadas tem conduzido as análises realizadas nesse subcampo especializado a manter uma articulação mais tênue com questões relativas ao processo de modernidade em sua fase contemporânea. O artigo enfatiza que a sociologia tem como um de seus desafios incontornáveis a tarefa de recolocar na sua pauta de pesquisa a análise dos sistemas de ensino preservando a perspectiva macro analítica delineada por determinados autores clássicos.

Palavras-chave: Modernidade. Sociologia. Sistemas de ensino. Subcampos da sociologia. Ensino superior.

\footnotetext{
* Professor Titular do Departamento de Sociologia da Universidade de Brasília (Brasil). Doutor em Sociologia pela Universidade de Paris V (França). Realizou Pós-doutorado na Universidade de Columbia (EUA). Atualmente é Pesquisador-Visitante na Universidade de Oxford (Reino Unido).E-mail: carlosb@unb.br
} 


\section{Sociology and higher education: convergence or divergence?}

\section{Abstract}

This article explores particular frameworks which have characterized the relation between sociology and the analysis of education systems in the modernity, with emphasis on the higher education system. It points out that the issue of education has taken a noticeable position in the work of some classical authors in the field of sociology when analyzing the constitution of modernity. It also emphasizes that the education system, in particular the higher education system, has held a strategic position in contemporary societies due to the complex relation it has with the economic, political and cultural spheres in distinct societal contexts. The text highlights the tendency of contemporary sociology to approach the education system as one of its sub-fields. In addition, it shows that the tendency of looking into the higher education system from different disciplinary perspectives has led the analysis conducted on this sub-field to have a weaker connection with matters related to the process of modernity in its contemporary stage. The paper emphasizes that one of sociology's main challenges is to bring the analysis on the education systems back to its research agenda and keep the macro-analytical perspective drawn up by certain classical authors.

Keywords: Modernity. Sociology. Education systems. Sociology sub-fields. Higher Education.

\section{Introdução}

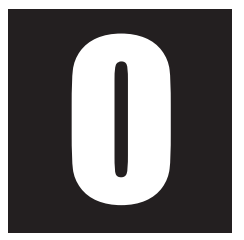

presente artigo parte do pressuposto que a reflexão entre o processo de constituição e posterior trajetória da modernidade e os sistemas de ensino nacionais, ou seja, a rede de instituições de educação formal existentes no interior das diversas sociedades nacionais constitui um desafio crucial para as ciências sociais na atualidade, destacadamente para a sociologia, em função da posição relevante que as instituições de ensino têm ocupado na esfera cultural da modernidade. 
Entre os diferentes níveis do sistema de ensino, o artigo privilegiou como referência o ensino superior, devido às complexas relações que mantém com o processo de desenvolvimento econômico, com a produção de conhecimento técnico e científico, com as crescentes exigências sociopolíticas de democratização e de igualdade de oportunidades nas sociedades contemporâneas.

No entanto, apesar da imbricação que os sistemas de ensino nacionais possuem com os campos econômico, político e cultural das sociedades contemporâneas, cumpre indagar: como se situa a temática da educação, destacadamente a de nível superior, enquanto tendência, no interior da sociologia como disciplina?

Uma resposta plausível a essa questão implica necessariamente uma rigorosa investigação comparativa entre determinados países, procurando analisar o processo de formação de suas respectivas sociologias nacionais, apreender a posição da temática da educação no interior da hierarquia de prestígio que as sociologias nacionais atribuem aos objetos de pesquisa, bem como a reconstrução histórica dos seus sistemas de ensino nacionais, ou seja, um amplo empreendimento intelectual coletivo que pressupõe a mobilização de cientistas sociais dos países a serem comparados. Afastando-se do propósito de assumir tal empreitada científica, sem dúvida relevante e promissora em termos de produção de conhecimento, o presente artigo possui como escopo destacar, de forma esquemática, determinados marcos que têm caracterizado a relação entre sociologia e sistemas de ensino na modernidade, particularmente a relação entre sociologia e ensino superior.

Nas páginas finais do livro The coming crises of western sociology, Alvin Gouldner reivindicava a relevância da incorporação de uma sociologia reflexiva na prática cotidiana do trabalho sociológico. Longe de postular a criação de uma nova subdisciplina, Gouldner concebia a sociologia refle- 
xiva como uma estratégia de autorreflexão crítica realizada pelo sociólogo, a qual poderia contribuir de maneira efetiva para elucidar as condições históricas que influenciam os contornos do seu campo específico de investigação, capaz de permitir a compreensão do contexto institucional que permeia a sua prática profissional, bem como possibilitar o contínuo questionamento de suas crenças acadêmicas e ações praticadas interior do campo.

Para Gouldner, com frequência, utilizamos a sociologia para criticar e/ou desqualificar de forma impiedosa o trabalho realizado por outros sociólogos que mobilizam perspectivas analíticas divergentes das que consideramos as mais adequadas e raramente como uma forma de questionar nossas adesões teórico-conceituais e de problematizar a estruturação e o funcionamento do universo particular de pesquisa no qual nos encontramos inseridos. Alguns anos depois, na mesma direção de reflexão, Pierre Bourdieu ressaltou que a incorporação rotineira da sociologia constitui uma disposição intelectual fundamental na produção do conhecimento quando o pesquisador a utiliza não como uma arma de combate contra os outros, mas como uma ferramenta crítica voltada para si mesmo, ou seja, enquanto instrumento de autorreflexão que o habilita a refletir criticamente sobre a complexa relação que o sociólogo estabelece com as crenças acadêmicas, nem sempre aparentes e visíveis, as quais estruturam seu campo específico de pesquisa (Gouldner, 1970; Bourdieu, 1980, 1982).

O artigo incorpora, de forma subjacente e discreta, a contribuição de uma pluralidade de autores, que, apesar de suas diferenças teóricas, têm oferecido contribuições diretas e/ou indiretas para compreender determinadas fases da formação do campo da sociologia voltada para a análise dos sistemas educacionais na modernidade, tendo como tela de fundo as condições histórico-sociais e o contexto acadêmico-institucional que permearam esse processo. Portanto, procura-se refletir, de maneira breve e esquemática, a partir do ângulo da sociologia, sobre a formação 
de um subcampo disciplinar no âmbito da sociologia que, gradativamente, passou a dedicar-se à analise dos sistemas educacionais (Gumport, 2007; Camic, 2004; Abbott, 2002; Cole, 2001; Becher e Trowler, 2001; Swindler, 1994, p. 305-329; Crane, 1972; Friedrichs, 1970; Gouldner, 1970; Manheimm, 1968).

De forma deliberada, o artigo encontra-se descolado de referências empíricas imediatas, uma vez que se pretende esboçar um quadro de referência abrangente a respeito da relação entre sociologia e sistemas de ensino na modernidade. Nesse sentido, adota-se uma perspectiva próxima ao conceito de tipo ideal weberiano. Como se sabe, na visão de Weber a construção de tipos ideais representava um recurso heurístico para ordenar intelectualmente o conhecimento da realidade, constituindo um quadro de pensamento, um conceito-limite. Para Weber, era impossível encontrar empiricamente os tipos ideais na realidade concreta, uma vez que, na sua pureza conceitual, eles se aproximam de uma utopia. Nessa direção, a expressão "relação entre sociologia e sistemas de ensino na modernidade" procura acentuar determinados acontecimentos da vida histórica e/ou pontos de vista para formar um cosmo de relações pensadas, mediante a acentuação mental de certos elementos da realidade (Weber, 1974).

\section{Modernidade, Sociologia e Sistema Educacional}

Apesar da existência de um relativo consenso no interior da sociologia a propósito da dimensão estratégica dos sistemas educacionais nas sociedades contemporâneas, percebe-se que a temática educacional tende a ocupar uma débil presença nos trabalhos que enfocam a questão da modernidade em sua fase atual. Não seria incorreto afirmar que a relação entre modernidade e educação desfrutou uma presença relevante no período de formação da sociologia, expressa na obra de determinados auto- 
res clássicos da disciplina. No entanto, quando se avança para o período mais recente, é possível perceber, salvo exceções, um modesto tratamento conferido ao sistema educacional na obra de autores significativos, os quais vêm se dedicando a analisar o processo de constituição e transformação da modernidade, tais como Jürgen Habermas, Anthony Giddens, Arjun Appadurai, Stuart Hall, Ulrich Beck, Zygmunt Bauman, Manuel Castels, etc. Caso seja procedente a suposição de que a temática dos sistemas educativos tende a ocupar uma posição relativamente discreta nos trabalhos dedicados à análise das múltiplas dimensões da modernidade em sua fase atual, seria oportuno indagar quais as circunstâncias que têm contribuído para sua pálida presença no interior desses trabalhos?

O artigo parte da suposição de que, apesar de ter ocorrido um aumento significativo de trabalhos acadêmicos voltados para a temática do ensino superior, divulgados em uma gama variada de periódicos nacionais e internacionais, sua abordagem, enquanto tendência, tem concentrado em temas especializados, tais como financiamento da educação, gestão do sistema universitário, etc. Em decorrência dessa especialização, a análise sociológica do ensino superior tende a manter uma menor articulação com questões relativas ao processo de modernidade em sua fase contemporânea.

O conceito de modernidade empregado neste artigo refere-se a um feixe de instituições típicas e processos sociais que emergiram na Europa a partir do século XVII, tais como progressiva racionalização e diferenciação econômica e administrativa do mundo social, formação do moderno Estado capitalista-industrial, introdução de novas formas de relacionamento social baseadas no contrato e não mais na tradição e no carisma, formação de classes sociais, processo de proletarização, progressiva substituição de procedimentos de formas tradicionais de conhecimentos realizada pela ciência e tecnologia de base experimental, etc. Os marcos dessa nova ordem foram a revolução industrial, a revolução francesa e a formação dos 
Estados-nação. As instituições que emergiram com a modernidade, gradativamente, tornaram-se presentes em escala universal, assumindo configurações históricas bastante variadas, dependendo de cada contexto concreto específico. Na reconstrução que efetuou sobre o conceito de modernidade, Habermas, recorrendo a Hegel, assinalou que o seu emprego refere-se a contextos históricos, como conceitos de época: os "novos tempos" são os "tempos modernos". A descoberta do "novo mundo", assim como o renascimento e a reforma constituem o limiar histórico entre a época moderna e a medieval. Para Habermas, o conceito de "tempos modernos" expressa a convicção de que o futuro já começou: indica a época orientada para o futuro, uma época que se encontra irremediavelmente aberta ao novo, aos acontecimentos que haverão de vir. Com isso, a ruptura em que se inicia o novo é deslocada para o passado, precisamente para o começo da época moderna: somente no século XVIII, o limiar histórico em torno de 1500 foi compreendido retrospectivamente como tal começo (Hall, 2005; Habermas, 2000; Featherstone, 1995).

A esfera cultural, ao longo de um processo histórico, tornou-se uma das dimensões institucionais centrais da própria modernidade. O desenvolvimento do processo de secularização da vida cultural, desencadeado pelo renascimento, pela revolução científica propiciou a constituição de uma diversidade de instituições que passaram a integrar com dinamismo a esfera cultural da modernidade em sua etapa inicial, tais como as instituições escolares, as academias de ciência, as universidades que tiveram um papel importante no desenvolvimento material e intelectual de suas respectivas sociedades. A partir do século XVIII aproximadamente, tornou-se possível seguir uma carreira intelectual como professor, mas também como escritor ou membro assalariado das academias de ciência que surgiram em algumas capitais europeias. O modelo de universidade concebida por Humbolt em 1810 - o qual procurava proclamar a auto- 
nomia institucional da universidade diante das demandas da religião e do Estado e, ao mesmo tempo, assumir uma posição estratégica na produção da pesquisa, no desenvolvimento do conhecimento e na formação de profissionais de elevado padrão intelectual - espalhou-se pelos quatro cantos do mundo (Orstein, 1938; Fallon, 1980; McClelland, 1980)

Em um momento posterior, a progressiva intensificação do processo de autonomização da esfera cultural propiciou o surgimento do movimento modernista, entre 1870-1930, em vários países europeus. Seus participantes, através de uma diversidade de obras produzidas nos campos da literatura, da pintura, da música clássica, expressavam um sentimento de ambiguidade diante da própria constituição da modernidade, ora afirmando, ora negando as novas formas de vida que estavam em processo de gestação. Através de uma multiplicidade de trabalhos, os modernistas colocaram em evidência o potencial dinâmico da esfera cultural na modernidade e sua capacidade de interpretá-la e de influir na formação da consciência e no comportamento dos atores sociais nas sociedades modernas. Na ácida avaliação de Daniel Bell, a propagação da cultura modernista passou a ser um elemento constitutivo da própria modernidade e, ao mesmo tempo, representou uma força corrosiva, uma vez que passou a produzir uma cultura marcadamente crítica e adversária do capitalismo, a qual, em conjugação com a cultura hedonista que aflorou na metade dos anos 1960, contribuiria para subverter os valores burgueses tradicionais e a ética puritana do trabalho (Scott, 2006; Wilson, 2004; Berman, 1986; Frisby, 1985; Bell, 1976).

Tal como o movimento modernista, o surgimento da sociologia no século XIX representou um produto, um desdobramento cultural da constituição do processo de modernidade. Ao mesmo tempo, a nova disciplina expressou uma das formas de elaboração de uma autoconsciência intelectual da emergência da modernidade. A formação da sociologia representou 
um projeto intelectual inovador, visando compreender analiticamente as profundas mudanças econômicas, culturais, políticas, as novas formas de pensar, sentir e comportar dos atores sociais, produzidas pela modernidade, de tal forma que o pensamento sociológico clássico privilegiou essa temática como seu objeto de reflexão. Como assinalou Robert Nisbet, em seu clássico trabalho The Sociological Tradition, foi no conflito entre tradição e modernidade que emergiram alguns dos conceitos antinômicos fundamentais da sociologia, tais como "comunidade-sociedade", "autoridadepoder", "status-classe", "sagrado-secular", "alienação-progresso", os quais foram elaborados a partir de distintas perspectivas analíticas. A diversidade teórica e a exploração de múltiplos aspectos que comportam a modernidade, que esteve presente nos autores clássicos, têm permanecido na análise de trabalhos desenvolvidos no contexto da sociologia contemporânea, o que levou Danillo Martucelli a postular a existência de "sociologias" da modernidade (Martucelli, 1999; Nisbet, 1966).

Durante o século XIX, na Europa e nos EUA, sistemas escolares de massa foram construídos e a educação compulsória foi introduzida. O ensino superior estava, nesse momento, basicamente estruturado na existência de universidades, cuja origem remonta à Idade Média, de tal forma que esses dois termos eram praticamente equivalentes. Até 1300, existiam no mundo ocidental não mais que 15 universidades; em 1500, esse número aumentou para 50, saltando, em 1700, para 95 unidades. Em 1850, havia aproximadamente 150 universidades no Ocidente (Verger e Charle, 1994; Verger, 1986; Haskins, 1977; Cobban, 1975).

A universidade ocupou uma centralidade no contexto das instituições culturais da modernidade. Em função de suas atividades de ensino, de seus produtos culturais e científicos, a universidade, nos períodos iniciais da modernidade, estruturou-se como uma instituição sui generis, mantendo uma posição relativamente isolada diante da vida econômi- 
ca e política, voltada fundamentalmente para seus afazeres específicos, buscando assumir uma posição de independência institucional diante das demandas externas. No contexto da formação dos estados-nacionais, as universidades usufruíram um grande prestígio social e foi considerada como uma instituição imprescindível para a formação dos quadros das elites culturais, econômicas e políticas das sociedades modernas (Scott, 2006; Delanty, 2001; Shils, 2001).

A simultaneidade entre o surgimento de sistemas escolares em diversos países e a emergência do processo de constituição da modernidade propiciou à educação um caráter explicativo tão forte como outros temas caros às ciências sociais, como o trabalho, classes sociais, Estado, etc. Entre determinados autores clássicos da sociologia, tais como Durkheim e Weber, a educação formal foi analisada - a partir de perspectivas analíticas divergentes como uma instituição relevante no processo de formação deste novo momento histórico vivenciado por determinadas sociedades em razão das múltiplas funções que ela passou a exercer no contexto de diferentes sociedades nacionais, de tal forma que a abordagem do sistema educacional foi intimamente articulada com a emergência do processo de modernidade. No entanto, tudo leva a crer que, ao longo do desenvolvimento da sociologia, a temática dos sistemas educacionais passou a ser praticada em um subcampo especializado da sociologia, tal como temia Florestan Fernandes, defensor da sociologia como disciplina unitária. Em sua visão, os instrumentos teóricos, conceituais e metodológicos desenvolvidos pela sociologia podem ser aplicados frutiferamente à análise e à explicação de qualquer fenômeno social. Nesse sentido, não percebia justificações epistemológicas, teóricas e sociológicas para a existência de subdisciplinas especiais estruturadas a partir de objetos e procedimentos específicos no interior da própria sociologia (Fernandes, 1960). 
Não se trata aqui de realizar um inventário da temática da educação no interior da sociologia através de determinados autores, mas apenas destacar brevemente alguns marcos dessa trajetória. Nesse sentido, procura-se ressaltar que, de forma geral, as análises realizadas por determinados autores considerados clássicos da sociologia revelam que a abordagem do sistema educacional foi realizada a partir de uma ampla perspectiva analítica, na qual o sistema educativo e a constituição da modernidade encontravam-se intimamente articulados. De modo geral, essas análises foram realizadas em um contexto universitário, no qual o processo de especialização e fragmentação disciplinar começava a dar seus primeiros passos, o que lhes permitiu abordar a temática da educação a partir de perspectiva macroanalítica. Determinados autores clássicos, especialmente Durkheim e Weber, conferiram um tratamento aos sistemas educacionais que os cercavam; e suas análises, apesar das diferenças teóricas, contribuíram para imprimir uma macroperspectiva na apreensão da educação, colocando em evidência sua imbricação com as esferas econômica, política e cultural. Os sistemas educativos aparecem em suas análises possuindo funções sociais significativas, seja no processo de integração social, seja no processo de racionalização da cultura, nas políticas de planejamento social, etc. Devido à abrangência teórica de tais análises sobre a questão educacional, articulando-a com questões mais gerais da constituição da modernidade, a herança intelectual legada pelos clássicos continua a oferecer pontos de referência estimulantes para (re)pensar o ensino superior nas sociedades contemporâneas (Heilbron, 2006; Ringer, 2002; Clark, 1973; Wallerstein, 1996).

Entre os clássicos, Durkheim foi o autor que conferiu um tratamento sistemático ao tema da educação, sendo que, no início de sua carreira, ministrou aulas na Faculdade de Educação de Bourdeaux, lecionando sobre o método e a disciplina pedagógicos. Em seu clássico trabalho Édu- 
cation et Sociologie, assinalava que a análise dos sistemas educativos só é compreensível quando se levam em consideração os contextos históricos que os permeiam. Em sua visão, o sistema educativo, mesmo possuindo uma certa autonomia institucional, mantém relações de interdependência com a organização política, com a religião, com o grau de desenvolvimento da ciência, da vida industrial, ou seja, ele se encontra articulado com diversas esferas constitutivas da vida social. Seus trabalhos ressaltaram a dimensão moral da educação, uma vez que ela não pode ser entendida como mera transmissão de conhecimentos instrumentais. Ao analisar a modernidade como um processo de transição da solidariedade mecânica para orgânica, a preocupação com a ordem social emergiu como uma questão central para ele.

A temática da educação foi trabalhada em sua obra como uma instituição fundamental para a manutenção do equilíbrio social das sociedades modernas, por mais que Durkheim procurasse conferir uma certa autonomia aos indivíduos. Em seu entendimento, a educação deveria transmitir valores comuns a todos os membros de uma determinada sociedade e, ao mesmo tempo, valores específicos para os diferentes grupos sociais em função do processo de diferenciação social. Na medida em que a educação deveria produzir nos indivíduos uma comunidade de ideias e de sentimentos, sem a qual a existência de uma sociedade tornarse-ia inviável, o Estado, na visão do autor, teria uma centralidade na oferta e no controle da rede escolar. Em seu entendimento, o Estado, no cumprimento de seus deveres, deveria afastar-se de orientações partidárias e/ ou particularistas e pautar-se por valores universalistas, tais como respeito à razão e à ciência (Durkheim, 1980, 1990; Lukes, 1973).

Determinadas reflexões elaboradas por Max Weber sobre a temática da educação possuem também uma ampla perspectiva analítica. Ao analisar a dominação racional-legal, chamou a atenção para os seus efeitos 
sobre as instituições educacionais e a natureza do treinamento educacional: com o processo de burocratização, os ginásios, as escolas técnicas e as universidades no continente europeu passaram a ser dominadas por uma educação cada vez mais especializada, relegando o ideal de formação de um "homem culto" em prol da produção de peritos, e submetida a um crescente sistema de exames racionais que tenderia a se generalizar em todo o mundo. Os títulos educacionais passariam a ser um pré-requisito para cargos nas burocracias públicas ou privadas, gozariam de um crescente prestígio social e seriam utilizados para obter vantagens econômicas. Suas interpretações sobre o processo de racionalização da cultura e o clamor universal do desenvolvimento do diploma universitário permanecem uma fonte intelectual inspiradora para analisar o sistema educativo na modernidade em sua fase atual. Weber realizou um estudo seminal para a compreensão da lógica do funcionamento dos sistemas de ensino a partir dos letrados chineses, no qual salientava que, durante doze séculos, a posição social na China foi determinada mais pelas qualificações para ocupação dos cargos do que pela riqueza material (Weber, 1969; Sadri, 1992).

Em um momento posterior, a temática da educação ocupou também um lugar central nas obras de Gramsci e de Mannheim, associada à preocupação de ambos os autores com a questão do papel dos intelectuais na sociedade moderna. Suas análises, construídas a partir de orientações teóricas distintas, colocam em relevo o papel central da instituição escolar na produção de quadros intelectuais e/ou profissionais especializados e sua relação com o mundo da economia, da política e da cultura. Nesse sentido, seus trabalhos permanecem referências teóricas importantes para (re)pensar sociologicamente os sistemas de ensino superior na atualidade.

Para Gramsci, o enorme desenvolvimento alcançado pela atividade escolar que surgiu no mundo medieval e se expandiu nas sociedades modernas coloca em destaque a importância de examinar a produção 
de diferentes categorias de intelectuais geradas no interior dos sistemas educacionais. Em sua visão, a instituição escolar é o instrumento fundamental para elaborar os intelectuais tradicionais ou orgânicos na sociedade moderna. Os intelectuais orgânicos de tipo urbano, contrapostos aos de tipo rural (em sua maior parte "tradicionais"), cresceram juntamente com a indústria, com as empresas que os usavam para organizar interesses e conquistar mais poder. Para o autor, no mundo moderno, a categoria dos intelectuais, mediada pelo sistema escolar, ampliou-se de forma considerável, nem sempre justificada pelas necessidades sociais de produção, mas decorrente, sobretudo, das necessidades políticas do grupo fundamental dominante. Ao enfocar a tendência de superprodução de intelectuais realizada pelo sistema escolar e suas consequências, tais como concorrência, desemprego de profissionais qualificados e emigração, sua análise levanta questões relevantes para refletir sobre a dinâmica dos sistemas de ensino superior na atualidade, tais como o processo de crescente massificação, a existência de uma assimetria entre oferta e demanda de pessoal qualificado e o potencial de tensões sociais e ressentimentos subjetivos derivados dessa situação de estandardização (Said, 2005; Bobbio, 1997; Gramsci, 1968).

Determinados aspectos da análise weberiana seriam retomados por pensadores da escola de Frankfurt, que mantiveram também uma ampla perspectiva ao analisar a temática da educação em um contexto histórico mais saliente do processo de desenvolvimento da modernidade. Nesse sentido, destacaram o impacto do crescimento do processo de racionalidade instrumental no mundo da cultura, (re)trabalhados a partir das contribuições das perspectivas marxista e freudiana. Na Dialética do Esclarecimento, uma das obras expressivas dessa tradição, o esclarecimento aparece como um processo que domina os espaços da práxis, da reflexão artística, tornando-se assim irracionalismo, e trazendo a barbárie massificadora, cujo exemplo maior seria o nazismo. Diretamente relacionado ao capitalismo, o 
esclarecimento torna-se a ideologia intransponível deste regime e, segundo essa visão, a educação institucional tenderia a contribuir para este processo (Wiggerhauss, 2002; Adorno, 1986; Horkheimer, 1976).

A análise de Mannheim procurará descolar uma relação unívoca entre intelectuais e sua inserção nos trabalhos de dominação social e/ou defesa imediata ou mediata de interesses específicos da classe dominante. Para ele, os intelectuais constituem um agregado situado entre as e não acima das classes sociais. O membro individual da intelligentsia pode ter, segundo ele, uma orientação particular de classe e, em conflitos reais, pode alinhar-se com um ou outro partido político. Mas, além e acima dessas afiliações, ele é motivado a encarar os problemas da sociedade a partir de várias perspectivas, e não apenas de uma só, em função de seu treinamento específico. A sociologia, em seu entendimento, constituía um instrumento teórico e prático fundamental para alcançar uma síntese das perspectivas e a partir daí viabilizar o planejamento racional das sociedades modernas. Nesse contexto, a educação surge como uma técnica social relevante no planejamento da liberdade, capaz de contribuir para a construção de uma democracia de bem-estar social e da edificação de uma ordem social cooperativa (Jacoby, 2001; Mannheim, 1982, 1974, 1968, 1940).

Algumas das temáticas trabalhadas por Durkheim seriam retomadas por Talcott Parsons também em uma perspectiva abrangente no contexto de seu projeto de edificar uma teoria geral da ação humana. Parsons compartilhava com os autores clássicos do século XIX a visão macrossociológica na análise do sistema educacional, abordando-o nas suas interdependências com as outras instituições sociais, atribuindo-lhe a importante função de realizar o processo de socialização dos atores sociais e de contribuir para o equilíbrio da ordem social. Sua análise é pautada na experiência norte-americana, considerada por ele como um exemplo a ser seguido. Em trabalhos como The American University, Parsons acentua que a "revolução 
educacional", ampliando a educação básica pública e universal, constitui um elemento central para a explicação da modernidade norte-americana, juntamente com as revoluções democrática e industrial.

O sistema educacional desempenha uma função relevante na constituição dos papéis sociais, e suas instituições permitem a inter-relação entre os diferentes níveis de análise, proposto pelo esquema conceitual do autor (sistema cultural, social e de personalidade). A expansão educacional é central em sua concepção de modernidade: ela teria reduzido a ignorância e desenvolvido a capacidade dos indivíduos e da sociedade em utilizar o conhecimento em prol do interesse humano e da implementação de valores modernos. Sua perspectiva analítica incentivou, em determinados círculos intelectuais (como os teóricos do capital humano), o otimismo para com a educação, que passou a ser sobrevalorizada como principal instituição promotora de desenvolvimento e integração social. A concepção parsoniana foi questionada em sua crença de igualdade de oportunidades educacionais por diversos autores, entre os quais Pierre Bourdieu (Bourdieu, 1990).

\section{Sociologia e Ensino Superior nas sociedades contemporâneas}

Entre as diversas análises sociológicas preocupadas em apreender determinados contornos salientes das sociedades contemporâneas, Anthony Giddens ressalta que estas entraram em uma fase de alta modernidade em decorrência da penetração e da influência das suas instituições constitutivas (industrialismo, capitalismo, vigilância, poder militar) em escala mundial. Em sua visão, os modos de vida produzidos pela modernidade desvencilharam os indivíduos dos tipos tradicionais de ordem social, de uma maneira sem precedentes, tanto em sua intensidade quanto em sua extensão - conforme diferentes áreas do globo são pos- 
tas em interconexão, ondas de transformações sociais penetram toda a superfície do planeta - as mudanças envolvidas na modernidade são mais profundas que a maioria dos tipos de mudança experimentados em períodos precedentes. $\mathrm{O}$ advento da modernidade, na percepção desse autor, acarreta alterações nas esferas da família, do trabalho, da política, da subjetividade, cria um mundo repleto de oportunidades e de riscos, no qual, devido ao seu dinamismo, as ações coletivas e individuais estão sujeitas a consequências imprevistas. Segundo sua perspectiva, em vez de entrarmos em um período de pós-modernidade, como é postulado em algumas análises, vide Lyotard, Baudriallard, Bauman, etc., a sociedade contemporânea estaria experimentando a radicalização e a universalização das consequências do processo da modernidade iniciada a partir do século XVII. (Giddens, 2003, 1991).

A partir da década de 1960, o ensino superior começou a dar sinais de transformações estruturais em escala internacional. Ocorreu um vertiginoso crescimento do número de universidades: em 1900, contavamse 250 instituições universitárias no Ocidente; em 1940, registravam-se 400 estabelecimentos universitários e, em 1970, podiam-se contar aproximadamente 920 universidades no mundo. Nas décadas seguintes, o processo de surgimento de novas universidades intensificou-se em escala internacional (UNESCO, 1999; Delanty, 2001).

O relativo isolamento da universidade diante das demandas da vida econômica, social e política começou a ser abalado, uma vez que passou a confrontar-se com uma variada gama de pressões sociais, econômicas e políticas, advindas de distintos atores sociais, tais como burocracias públicas e privadas, movimentos sociais, no sentido de estabelecer uma interação mais dinâmica com a sociedade contemporânea. Essa pressão forçou as instituições a rever suas atribuições acadêmicas e sua identidade institucional. Sua legitimidade cultural e social foi colocada em questiona- 
mento, no final dos anos 1960, por um movimento estudantil que eclodiu em várias partes do mundo e pelo movimento de contracultura, os quais abalaram a confiança e o orgulho das universidades tanto no seu meio interno quanto na sua relação com a sociedade. Paralelamente, surgiram novos e variados formatos institucionais de ensino superior, ou seja, estabelecimentos não universitários, voltados para o treinamento mais especializado, que passaram a coexistir com o modelo universitário. Iniciouse a corrosão da equivalência entre ensino superior e universidade que prevaleceu por um longo período histórico. As matrículas expandiram de forma vertiginosa em todos os continentes e a conversão líquida e certa dos diplomas no mercado de trabalho começou a ficar mais incerta e problemática. (Dougherty, 2007; Schofer e Meyer, 2005; Shils, 2001; Trow, 1973; Riesman e Jenks, 1968).

Essas profundas transformações contribuíram para trazer o ensino superior para o centro de um amplo debate público em escala internacional. Determinadas análises e reflexões ressaltaram a histórica relação que as instituições de ensino superior mantiveram com o processo de reprodução dos grupos dominantes, dos seus vínculos com o poder econômico e político e a corrosão de valores intrínsecos da vida universitária. Simultaneamente, outras visões ressaltavam que as instituições universitárias possuíam no seu interior um potencial capaz de contribuir para o processo de democratização das sociedades contemporâneas, de impulsionar a inovação cultural nas sociedades contemporâneas, de formar indivíduos dotados de autonomia intelectual. Esse debate, que ocorreu no final dos anos 1960, mobilizou cientistas sociais de diferentes países, mas também líderes estudantis, policy makers, organismos internacionais envolvidos com a educação superior de seus países membros, jornalistas, e uma variada gama de intelectuais, etc (Morin e Castoriadis, 2008; Aronowitz, 2000; Gitlin, 1993; Fraser, 1988; Keer, 1982; Nisbet, 1971; Touraine, 1971, 1972). 
Paralelamente, foi se constituindo, a partir do final dos anos 1960, em diversas sociologias nacionais, um processo de edificar o tratamento de questões educacionais, a análise dos sistemas educacionais, no interior de uma sociologia especializada - a sociologia da educação. Em um momento posterior, como desdobramento desse processo de formação de sociologias especializadas, passou a ocorrer, em diversas sociologias nacionais, a emergência da sociologia do ensino superior enquanto um subcampo da sociologia da educação, voltado para a análise dos sistemas de ensino superior das sociedades contemporâneas. Esse processo de produção de conhecimento praticado por especialistas, tendo como alvo a comunicação com especialistas e utilizando nessa relação de comunicação revistas especializadas, tendeu a gerar um circuito acadêmico fechado em si mesmo. Com isso, abriu-se um espaço nas diferentes sociedades nacionais para que determinados atores, tais como dirigentes das instituições de ensino superior, associações de reitores, policy makers de agências nacionais e internacionais de planejamento do ensino superior, jornalistas que atuam na imprensa escrita e televisiva assumissem a dianteira da formulação da agenda do debate público sobre os diferentes níveis do sistema de ensino, inclusive o de nível superior (Poupeau, 2003; Coulon e Neves, 1990; Torres, 1998).

Ao refletir sobre o sistema de ensino superior, Craig Calhoun ressalta que, desde o final do século XIX, seu modelo organizacional das universidades foi incorporado em diversas sociedades nacionais. Em sua percepção, a instituição universitária assumiu uma centralidade na esfera pública de seus respectivos países, na medida em que forneceu simultaneamente treinamento profissional especializado e uma sólida base para a constituição da cidadania. Avaliando a produção da sociologia norte-americana voltada para a análise de seu próprio sistema de ensino superior, Craig CaIhoun enfatizou que, em décadas anteriores, houve uma maior atenção e 
preocupação por parte dos sociólogos norte-americanos em analisar suas instituições quando comparado com o período atual. Nesse sentido, destaca a presença da temática do ensino superior na obra de sociólogos que ocuparam posições destacadas na disciplina no contexto norte-americano, tais como David Riesman, Talcott Parsons, Peter Blau, Martin Trow e outras figuras centrais. Assinala que, com exceção de poucas publicações atuais, tais como a obra coletiva The Future of the city of knowlodge, organizada por Stephen Brint, e de alguns trabalhos de Stanley Aronowitz, a sociologia norte-americana, em sua fase contemporânea, não vem produzindo trabaIhos significativos sobre ensino superior, tal como ocorreu em um período anterior. Na visão de Calhoun, embora tenha aumentado o volume de produção de trabalhos voltados para a análise de ensino superior, uma das razões de sua pálida presença no contexto da sociologia deve-se à divisão de trabalho intelectual existente no interior das universidades norte-americanas entre as ciências sociais e as faculdades de educação que passaram, em larga medida, a se ocupar da temática do ensino superior. Nesse sentido, em sua avaliação, a sociologia deixou de emprestar uma contribuição para o debate público sobre o seu próprio sistema de ensino superior. (Calhoun, 2009, 2006a, 2006b; VanAntwerpen: 2006).

Ao colocar em relevo a influência do contexto da organização interna da universidade na produção do conhecimento acadêmico, Craig Calhoun ao lado de outros autores, fornece um marco para a compreensão do discreto impacto da temática dos sistemas de ensino superior no contexto da sociologia contemporânea. Um conjunto de análises tende a indicar que, gradativamente, ocorreram profundas mudanças na estruturação do trabalho intelectual operado nas universidades, nos diversos formatos de instituições de ensino e de pesquisa em várias sociedades nacionais, expressas através de uma crescente divisão de trabalho entre as diferentes disciplinas, edificação de fronteiras entre elas, criação de 
departamentos acadêmicos integrados por especialistas em suas respectivas disciplinas, proliferação de subdisciplinas especializadas, emergência de temas cada vez mais específicos no interior das subdisciplinas. Se, por um lado, em vários países a análise dos sistemas de ensino passou a ser um tema tendencialmente apropriado pelos institutos e/ou faculdades de educação, pelo corpo de pesquisadores em educação, por outro lado, a temática da modernidade, de sua constituição, transformações e contradições no mundo contemporâneo, vem sendo apossada pelas ciências sociais, destacadamente pela sociologia. Nesta direção, tendencialmente, passou a ocorrer um fosso significativo entre a análise dos sistemas de ensino superior e a sociologia. Ao mesmo tempo, os sociólogos que elegeram a temática do ensino superior dirigiram-se para um subcampo especializado no interior da sociologia, tal como a sociologia do ensino superior esboçada no contexto norte-americano por Burton Clark. Desta forma, passaram a adotar uma perspectiva cada vez mais especializada em subtemas, como a profissão acadêmica, estrutura organizacional das instituições, governo das universidades, desigualdades de classe, raça e gênero no acesso ao ensino superior, etc., levada a cabo por especialistas e dirigida fundamentalmente para os pares que atuam no mesmo subcampo disciplinar, utilizando em seu processo de comunicação publicações especializadas. Essa organização da estrutura universitária, sem dúvida, possibilitou o adensamento do tratamento de temas educacionais selecionados para pesquisa, tanto do ponto de vista teórico quanto do metodológico; no entanto, tem gerado um insulamento acadêmico dessas análises, confinando-as prioritariamente em um circuito acadêmico (Cark, 2008; Gumport, 2007; Abbott, 2002, 2001; Cole, 2001; Game e Metcalfe, 1996; Jacoby, 1990).

Nesse contexto de hiperespecialização do conhecimento, que vem abarcando praticamente todas as áreas de conhecimento e que possui 
como locus operacional as instituições acadêmicas, Craig Calhoum destaca como um contraexemplo de postura intelectual o trabalho desenvolvido por Pierre Bourdieu com relação a suas análises do ensino superior. Em sua visão, a obra de Bourdieu, especificamente Homo Academicus e La Noblesse d'État, apreende a estruturação e o funcionamento do ensino superior levando em consideração sua dimensão histórica e captando suas transformações no passado e no presente. Ressalta também que a concepção de campo formulada por Bourdieu permite analisar as lutas que ocorrem no seu interior, compreender o complexo processo de constituição de suas hierarquias de consagração, seja das instituições e/ou dos atores que nele atuam, mas, ao mesmo tempo, permite compreender as conexões que o campo universitário mantém com os campos do poder econômico e político. Seria oportuno acrescentar também que, ao longo de sua trajetória acadêmica, de forma deliberada, Bourdieu recusou-se a aceitar a existência de rígidas fronteiras entre as diferentes disciplinas das ciências sociais e se opôs ostensivamente à fragmentação da sociologia em torno de especializações temáticas e de subdisciplinas. Seus trabalhos procuraram manter uma perspectiva macrossociológica inaugurada pelos clássicos, enfocando os sistemas educativos em suas relações com a dinâmica das lutas simbólicas das classes sociais, analisando-os em sua interface com o mundo da cultura, com as diferentes instâncias do poder, com o processo de dominação, etc. (Poupeau, 2003; Berthelot, 2003; Martins, 2002).

No presente estágio de seu desenvolvimento, a sociologia encontrase diante de novos fenômenos, portadores de elevado grau de complexidade e menos conhecidos, quando comparados com os temas com os quais lidou ao longo de sua história .Nesse contexto, destaca-se o processo de globalização (econômica, política, cultural) que interligou a existência dos atores sociais com uma diversidade de fenômenos que ocorrem em uma escala mundial. O entrelaçamento recíproco das dimensões de 
fenômenos globais, regional e local engendrou novos objetos, tais como a intensificação do fluxo de informações, um aumento significativo de deslocamento de pessoas através de processos de migrações, um crescimento planetário de mobilidade espacial, o aparecimento de novas formas de desigualdades sociais, o surgimento de movimentos sociais globais, a constituição de uma sociedade civil em escala mundial, etc. Certamente, esses fenômenos permeiam os sistemas de ensino e afetam profundamente sua estruturação e funcionamento.

A diversidade de transformações que estão ocorrendo na sociedade contemporânea implica, por parte dos sociólogos, a necessidade de rever crítica e constantemente suas preferências teóricas e metodológicas e indagar sobre o grau de pertinência do arsenal teórico que vem informando seu olhar sobre a vida social e as análises realizadas sobre os sistemas de ensino. Na avalição de diversos autores, a sociologia encontra-se diante de vários percalços para enfrentar os desafios do tempo presente, tais como proliferação de subdisciplinas no interior da sociologia, fragmentação da sociologia em temáticas cada vez mais particularizadas, proliferação de estudos desconectados uns dos outros, negligência de reflexão teórica nos trabalhos empíricos, multiplicação de discursos metateóricos e/ou metametodológicos abstratos, os quais pouco contribuem para o avanço de investigação. Esses trabalhos ressaltam os riscos potenciais para a sociologia em persistir na exacerbação de cultivar temáticas cada vez mais particularizadas e mais particularistas. Advertem também que, longe de se confinar em suas fronteiras internas, de criar infindáveis subcampos temáticos, deve aprofundar o diálogo intelectual com as diversas disciplinas que integram o universo das ciências sociais e humanas. (Delanty, 2009; Silber, 2007; Kalberg, 2007; Caillé, 2007).

A sociologia tem diante de si, como uma de suas tarefas intelectuais inelutáveis, o desafio particular de (re)colocar a análise do sistema de 
ensino superior na fase atual da modernidade no centro de suas preocupações acadêmicas. Os pesquisadores que selecionaram essa temática de trabalho têm o desafio de conectar suas pesquisas com questões teóricas, conceituais, metodológicas pertinentes à sociologia como disciplina científica. A incorporação rotineira de uma sociologia da sociologia permanece como um recurso intelectual de grande valia no processo de autorreflexão crítica da prática sociológica e um poderoso antídoto contra um estéril confinamento em subcampos, em temas particulares e particularistas que têm pouco contribuído para alimentar a esfera pública das diversas sociedades e conferir uma relevância social para a sociologia nas sociedades contemporâneas.

\section{Referências}

ABBOTT, Andrew. The disciplines and the future. In: BRINT, Steve (Org.). The Future of the City of Intellect. Stanford: Stanford University Press, 2002.

ABBOTT, Andrew. Chaos of Disciplines. Chicago: University of Chicago Press, 2002.

ADORNO, Theodor; HORKHEIMER, Max. Dialética do Esclarecimento. Jorge Zahar Editor: Rio de Janeiro, 1986.

ARONOWITZ, Stanley. The knowledge factory: dismantling the corporate university and creating true higher education. Boston: Beacon, 2002.

BECHER, Tony; TROWLER, Paul. Academic Tribes and territories. Philadelphia: Open University Press, 2001.

BELL, Daniel. The cultural contraditions of capitalism. New York: Basic Books, 1996.

BERMAN, Marshall. Tudo que é sólido desmancha no ar: a aventura da modernidade. São Paulo: Companhia das Letras, 1986.

BOBBIO, Norberto. Os intelectuais e o poder: dúvidas e opções dos homens de cultura na sociedade contemporânea. São Paulo: Unesp, 1996.

BOURDIEU, Pierre. Questions de sociologie. Paris: Éditions de Minuit, 1980.

BOURDIEU, Pierre. Leçon sur la leçon. Paris: Éditions de Minuit, 1982. 
BOURDIEU, Pierre. La Noblesse D'Etat. Minuit. Paris, 1989.

CAILLÉ, Alain. Sociology as anti-utilitarianism. European Journal of Social Theory, $10(2), 2007$.

CALHOUN, Craig. Sociology in America. Chicago: University of Chicago Press, 2006a.

CALHOUN, Craig. Is the university in crisis? Society, maio/junho $2006 \mathrm{~b}$.

CALHOUN, Craig. Academic Freedom: public knowledge and the structural of the transformation university. Social Research, v. 76, n. 2, 2009.

CAMIC, Charles. The new Sociology of ideas. In: BLAU, Judith R. (Ed.). The Blackwell Companion to Sociology. Oxford: Blackwell Publisher, 2004.

CLARK, Burton. On Higher Education: selected writings (1956-2006). Baltimore: The Johns Hopkins University Press, 2008.

CLARK, Terry. Prophets and patrons: the French university and the emergence of social sciences. Massachusetts: Harvard University Press, 1973.

COBBAN, A. The medieval universities: their development and organization. London: Menthuen, 1975.

COLE, Stephen. What's wrong with sociology? New Brunswick: Transaction Publishers, 2001.

COULON, Alain; NEVES, Angela. Sociologie de l'Éducation: dix ans de recherche. Paris: L'Harmatan, 1990.

CRANE, Diane. Invisible Colleges: diffusion of knowledge in scientific communities. London: The University of Chicago Press, 1972.

DELANTY, Gerard. Challenging Knowledge: the university in the knowledge society. Philadelphia: Open University Press, 2001.

DELANTY, Gerard. The cosmopolitan imagination: the renewal of critical social theory. New York: Cambridge University Press, 2009.

DOUGHERTY, Kevin. Mass Higher Education: what is it impetus? What is it impact? Teachers College, v. 99. New York: Columbia University, 2007.

DURKHEIM, Emile. Éducationn et Sociologie. Paris: Puf, 1980.

DURKHEIM, Emile. L'evolution pédagogique en France. Paris: Puf, 1990.

FALLON, Daniel. The German university: a heroic idea in conlict with the modern world. Boulder: Colorado Associated University Press, 1980.

FRISBY, David. Fragments of Modernity. Oxford: Polity Press, 1985.

FEATHERSTONE, Mike. Global Modernities. London: Sage Publication, 1995. 
FRASER, Ronald. 1968: a student generation in revolt. New York: Pantheon, 1988. FRIEDRICHS, Robert. A Sociology of Sociology. New York: Free Press, 1970. FRISBY, David. Fragments of Modernity. Oxford: Polity Press, 1985.

GAME, Ann; METCALFE, Andrew. Passionate Sociology. London: Sage Publications, 1996.

GIDDENS, Anthony. The consequences for Modernity. Stanford: Stanford University Press, 1991.

GIDDENS, Anthony. Runaway world. How globalization is reshaping our lives. New York: Routledge, 2003.

GITLIN, Tood. Sixties: years of hope, days of rage. New York: Bantam Book, 1993. GOULDNER, Alvin. The Coming Crisis of Western Sociology. New York: Basic Books, 1970.

GRAMSCI, Antonio. Os intelectuais e a organização da cultura. Rio de Janeiro: Editora Civilização Brasileira, 1968.

GUMPORT, Patricia. (Org.). Sociology of Higher Education: contributions and their contexts. Baltimore: The Johns Hopkins University Press, 2007.

HABERMAS, Jürgen. Discurso Filosófico da Modernidade. São Paulo: Martins Fontes, 2002.

HALL, Stuart (Org). Modernity: an introduction to modern societies. Oxford: Blackwell Publishers, 2004.

HASKIN, Charles. The rise of Universities. New York: Ithaca, 1977.

HEILBRON, Johan. Naissance de la sociologie. Paris: Agone, 2006.

HORKHEIMER, Max. Eclipse da Razão. Rio de Janeiro: Editorial Labor do Brasil, 1976.

JACOBY, Russel. Os últimos intelectuais: a cultura americana na era da academia. São Paulo: Edusp, 1990.

JACOBY, Russel. O fim da utopia: política e cultura numa era da apatia. Rio de Janeiro: Record, 2001.

KALBERG, Stephen. A Cross-National Consensus on a Unify Sociological Theory? Some Inter-Cultural Obstacles. European Journal of Social Theory, (10) 2, 2007. KERR, Clark. The uses of universities. Cambridge: Havard University Press, 1982. LUKES, Steven. Émile Durlheim: his life and his work. Londres: The Penguin Press., 1973. 
MANNHEIM, Karl. Man and Society in an age of reconstruction. Londres: Routtledge and Kegan Paul, 1940.

MANNHEIM, Karl. Essays in the Sociology of Knowledge. Londres: Routledge, 1968.

MANNHEIM, Karl. Sociologia da Cultura. São Paulo: Edusp, 1974.

MANNHEIM, Karl. Ideologia e Utopia. Rio de Janeiro: Zahar, 1982.

MARTINS, Carlos, B. Notas sobre a teoria da prática em Bourdieu. Cadernos Cebrap, São Paulo, n.62, 2002.

MARTUCCELLI, Danilo. Sociologies de la modernité. Paris: Gallimard, 1999.

MORIN, Edgar; CASTORIADIS, Cornelius. Mai 68: la brèche: vingt ans après. Paris: Fayard, 1968.

NISBET, Robert. The Sociological Tradition. Londres: New Brunswick, 1966.

NISBET, Robert. The degradation of the academic dogma. The university in America (1945-1970). New York: Basic Book, 1971.

ORNSTEIN, Martha. The role of Scientific Societies in the Seventeenth century. Chicago: The University of Chicago Press, 1938.

POUPEAU, Frank. Une sociologie de l'État: I'école et ses experts en France. Paris: Raisons d'Agir, 2003.

RIESMAN, David; JENKS, Christopher. The academic revolution. New York: Doubleday, 1968.

RINGER, Fritz. The decline of the German mandarins: the German academic community, 1890-1933. Massachussets: Harvard University Press, 1996.

SAID, Edward. Representações do Intelectual. São Paulo: Companhia das Letras, 2005.

SADRI, Ahmad. Max Weber's sociology of intellectuals. New York: Oxford University Press, 1992.

SCHOFER, Evan; MEYER, John. The Worldwide Expansion of Higher Education in the Twentieth Century. American Sociological Review, vol. 70, 2005.

SHILS, Edward. The calling of education: the academic ethic and other essays on higher education. Chicago: The University of Chicago Press, 2001.

SILBER, Ilana. Toward a no unitary approach to general theory. European Journal of Social Theory, (10) 2, 2007.

TORRES, Carlos. Sociology of education: emerging perspectives. New York: State University of New York Press, 1998. 
TOURAINE, Alain. Le communisme utopique: le mouvement de mai. Paris: Seuil, 1971.

TOURAINE, Alain. Université et societé aux États-Unis. Paris: Seuil, 1972.

TROW, Martin. Problems in the transition from elite to mass higher education. Berkeley: Carnegie Commission on Higher Education, 1973.

UNESCO. Tendências da Educação Superior para o século XXI. Unesco, Brasília, 1999.

VANANTWERPEN, Jonathan. Critical Sociology and the interdisciplinary imagination. Thesis Eleven, n. 84, 2006.

VERGER, Jacques. Histoire des Universités en France. Toulouse: Privat, 1986.

VERGER, Jacques; CHARLE, Christophe. Histoire des Universités. Paris: PUF, 1994.

WALLERSTEIN, Immanuel (Org). Open the social Science. Report of the Gulbekian Commision on the restructuring of social sciences. Stanford: Stanford University Press, 1996.

WEBER, Max. Ensaios de Sociologia. São Paulo: Zahar Editores, 1969.

WEBER, Max. Sobre a Teoria das Ciências Sociais. Lisboa: Editorial Presença, 1974.

WILSON, Edmund. Axel's Castel: a study of imaginative literature 1870-1930. New York: Farrar, Strauss and Giroux, 2004.

Recebido em: 30/09/2011

Aceite final: 11/11/2011 